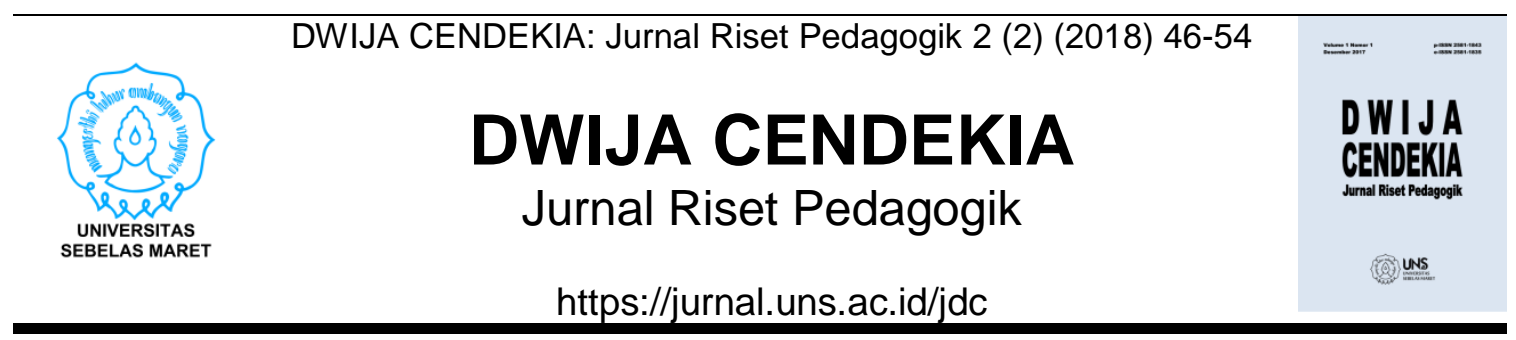

\title{
DEVELOPMENT OF MATHEMATICS AJAR MATERIALS BASED ON ETOPAPA (ETHNOMATEMATICS IN TOURISM OBJECTS OF PALEMBANG CITY)
}

\author{
Febriani Rotua Manullang, Miftha Indasari, Pranita Yuliana
}

Universitas PGRI Palembang

\section{Sejarah Artikel \\ Diterima 20 Oktober 2018 \\ Disetujui 26 Desember 2018 \\ Diterbitkan 31 Desember 2018}

Kata Kunci

Ethnomatematics,

Palembang Tourism,

Mathematical

Communication
Korespondensi Penulis:

febrianipgsd@yahoo.co.id

\begin{abstract}
Abstrak
This study aims to develop ETOPAPA-based mathematics teaching materials for elementary school students. Product trials were conducted using a pretest-posttest experiment group design. Data analysis techniques were carried out with item response analysis and t test. Validation test results on the feasibility of ETOPAPA-based mathematics teaching materials are in the very good category with a score of 4.45 . Analysis of the effectiveness of ETOPAPA-based mathematics teaching materials was carried out on the experimental class (E) and control class (K). Based on calculations obtained $\mathrm{E}>\mathrm{K}$, with an average $\mathrm{N}$-gain score of 0.64. The score is included in the interpretation of the medium category $(0.3 \leq \mathrm{g} \quad, 70.7)$. Based on these calculations, the application of ETOPAPA-based mathematics teaching materials was declared effective. The results of the practicality test of ETOPAPA-based mathematics teaching materials are in the practical category with a positive response and $85.02 \%$ student response. Based on the results of the analysis, it can be concluded that, learning flatter material using ETOPAPA based mathematics teaching materials at SDN 128 Palembang is valid, effective, and practical.
\end{abstract}

\section{Cara Mengutip}

Manullang, F., R., Indrasari, M., Yuliana, P. (2018). Development of Mathematics Ajar Materials Based on ETOPAPA (Ethnomatematics in Tourism Objects of Palembang City) . DWIJA CENDEKIA Jurnal Riset Pedagogik, 2 (2), 46-54 


\section{PENDAHULUAN}

Matematika sebagai salah satu ilmu dasar yang berkembang dengan pesat baik materi dan manfaatnya. Perkembangan matematika mendorong kemajuan teknologi serta mendorong untuk semakin cermat dalam menangkap fenomena yang terdapat dalam kehidupan sehari-hari manusia. Perkembangan matematika juga mempunyai pengaruh terhadap pelajaran dan pembelajaran matematika itu sendiri.

Berdasarkan hasil wawancara pada Debby guru SDNegeri 128 Palembang menyatakan: Pertama, tidak semua materi matematika bersifat kongkret dan terkadang mereka mengalami kesulitan dalam membuat media pembelajaran sehingga mereka lebih dominan mengajar menggunakan buku teks. Kedua, siswa terkadang masih bingung akan konsep-konsep dalam rumus matematika. Ketiga, siswa masih ragu dan takut untuk bertanya kepada guru atau bertanya kepada temannya sendiri walaupun dirinya belum paham dengan apa yang dipelajari. Keempat, siswa jarang dikelompokkan dalam pembelajaran matematika, sehingga kurang terjadi komunikasi antara siswa dengan siswa maupun siswa dengan guru.

Siswa mengalami kesulitan dalam belajar matematika khususnya komunikasi matematis, hal ini muncul karena adanya keabstrakan matematika dan seringkali muncul ketidaksesuaian dalam mempelajari matematika antara materi yang dipelajari dengan lingkungan dan tradisi budaya yang siswa temukandi sekolah maupun dikehidupan kesehariannya.

Proses pembelajaran di kelas, guru kurang memanfaatkan lingkungan khususnya nilai budaya. Kurangnya di kelas akan menyebabkan siswa kurang menghargai budaya yang ada dan tumbuh dilingkungan sekitar mereka salah satu wujud pembelajaran berbasis budaya adalah etnomatematika. Menurut Wahyuni (2013), etnomatematika adalah bentuk matematika yang dipengaruhi atau didasarkan budaya.

Hal ini didasarkan bahwa semua orang mempunyai kebutuhan mengemukakan ide, perasaan dan kebutuhan orang lain pada diri kita. Komunikasi merupakan bagian yang sangat dalam proses pembelajaran matematika karena melalui komunikasi, merenungkan, memperjelas dan memperluas ide dan pemahaman tentang matematika (Ontario, 2010). Selaras dengan pendapat diatas menurut Hartoyo (2012), Etnomatematika merupakan representasi kompleks dan dinamis yang menggambarkan pengaruh kultural penggunaan matematika dalam aplikasinya. Dalam pembelajaran berbasis etnomatematika, siswa dituntut untuk memahami budaya yang ada disekitar daerah mereka terkait materi yang akan diajarkan oleh guru.

Penelitian etnomatematika sebelumnya pernah dilaksanakan oleh Rahayu (2015) yang menyatakan bahwa kehadiran matematika yang bernuansa lingkungan sekitar dan budaya akan memberikan konstribusi yang besar terhadap matematika sekolah, karena sekolah merupakan institusi sosial yang berbeda dengan yang lain sehingga memungkinkan terjadinya sosialisasi budaya. Pendidikan dan budaya adalah sesuatu yang tidak bisa dihindari 
dalam kehidupan sehari-hari, karena budaya merupakan kesatuan yang utuh dan menyeluruh, berlaku dalam suatu masyarakat dan pendidikan merupakan kebutuhan mendasar bagi setiap inidividu dalam masyarakat.

Pendidikan, lingkungan dan budaya memiliki peran yang sangat penting dalam menumbuhkan dan mengembangakan nilai luhur bangsa, yang berdampak pada pembentukan karakter cinta budaya. Pemahaman budaya daerah yang dimiliki siswa masih rendah, banyak siswa yang lebih mengetahui budaya luar daerah bahkan budaya asing lebih mereka pahami. Pendidikan, lingkungan dan budaya memiliki peran yang sangat penting dalam menumbuhkan dan mengembangakan nilai luhur bangsa, yang berdampak pada pembentukan karakter cinta budaya. Pemahaman budaya daerah yang dimiliki siswa masih rendah, banyak siswa yang lebih mengetahui budaya luar daerah bahkan budaya asing lebih mereka pahami. Salah satu kebudayaan kota palembang dapat dilihat dari objek pariwisatanya, seperti jembatan ampera, benteng kuto besak, Monpera (monumen penderitaan rakyat), masjid cheng hoo, bukit siguntang, museum sultan mahmud badaruddin II, masjid agung sultan mahmud badaruddin I, gedung kantor walikota palembang, wisata alam hutan punti kayu, taman purbakala kerajaan sriwijaya, wisata kuliner martabak har, wisata kuliner pempek, museum tekstil, Museum negeri balaputeradewa, pusat kerajinan songket, pabrik pusri, jakabaring sport city

(sumber:

https://tempatwisataseru.com/tempatwisata-di-palembang/). Siswa sebagai besar mengetahui objek-objek wisata tersebut, tetapi siswa kurang memahami cara melestarikan objekobjek wisata kota palembang.

Berdasarkan Principles and Standards for School Mathematics dari NCTM (Agustyaningrum, 2011) indikator dari kemampuan komunikasi matematis siswa dapat dilihat dari beberapa aspek berikut.

1. Kemampuan menyatakan ide-ide matematis melalui tulisan, serta menggambarkan secara visual.

2. Kemampuan menginterpretasikan dan mengevaluasi ide-ide matematis baik secara tertulis.

a. Kemampuan siswa dalam menginterpretasikan

(menafsirkan) ide-ide matematis yang terdapat dalam persoalan matematika.
b. Kemampuan siswa dalam mengevaluasi ide-ide matematis

3. Kemampuan dalam menggunakan istilah-istilah, simbol-simbol matematika, dan strukturstrukturnya untuk memodelkan situasi atau permasalahan matematika.

Kaitannya dengan penelitian ini, indikator yang dipakai untuk menentukan kemampuan komunikasi matematis adalah kemampuan menyatakan ide-ide matematis melalui tulisan, serta menggambarkan secara visual, kemampuan menginterpretasikan dan mengevaluasi ide-ide matematis baik secara tertulis, kemampuan dalam menggunakan istilah-istilah, simbolsimbol matematika, dan strukturstrukturnya untuk memodelkan situasi atau permasalahan matematika.

Pengembangan bahan ajar matematika berbasis ETOPAPA dalam proses pembelajaran diharapkan menjadi alternatif yang efektif dalam meningkatkan kemampuan komunikasi matematis 
dan cinta budaya siswa. Dipilihnya sekolah dasar (SD) sebagai sasaran penelitian dimaksud agar nilai-nilai cinta budaya lokal dapat ditanamkan pada siswa sejak dini. Nilai-nilai tersebut harapannya akan tercermin pada tingkah laku mereka sehari-hari karena telah terbentuk pada kepribadiannya. Pendidikan formal atau sekolah menjadi institusi sangat penting yang bertugas menyemai dan mengembangkan nilai-nilai budaya lokal. Berdasarkan latar belakang inilah penulis tertarik untuk mencoba membuat tulisan ilmiah sederhana ini dengan judul "Pengembangan Bahan Ajar berbasis ETOPAPA (Etnomatematika pada Objek Pariwisata Kota Palembang)". Berdasarkan latar belakang, masalah penelitian ini dirumuskan sebagai berikut:
1. Apakah bahan ajar berbasis ETOPAPA materi bangun datar sekolah dasar valid?

2. Apakah bahan ajar berbasis ETOPAPA pada objek wisata palembang materi bangun datar sekolah dasar efektif?

3. Apakah bahan ajar berbasis ETOPAPA pada objek wisata palembang materi bangun datar sekolah dasar praktis?

Berdasarkan rumusan masalah tersebut maka tujuan yang hendak dicapai dalam penelitian ini adalah :

1. Menghasilkan bahan ajar berbasis ETOPAPA materi bangun datar sekolah dasar yang valid.

2. Menguji efetivitas bahan ajar berbasis ETOPAPA materi bangun datar sekolah dasar.

Menguji kepraktisan bahan ajar berbasis ETOPAPA materi bangun datar sekolah dasar.

\section{METODE PENELITIAN}

Adapun jenis penelitian yang digunakan adalah penelitian dan pengembangan (research and development/R\&D). Penelitian dan Pengembangan atau $R \& D$ adalah rangkaian proses atau langkah-langkah dalam rangka mengembangkan suatu produk baru atau menyempurnakan produk yang telah ada agar dapat dipertanggungjawabkan.

Pengembangan

perangkat pembelajaran yang digunakan dalam penelitian ini adalah model Plomp. Model pengembangan yang dikemukakan Plomp terdiri atas lima fase, yaitu fase investigasi awal (preliemary investigation), fase desain (design), fase realisasi/konstruksi

(realization/construction), fase tes, evaluasi, dan revisi (test, evaluation, and revision), dan fase implementasi (implementation) (Rochmad, 2013).

Agar mendapatkan data dan informasi yang lengkap mengenai hal-hal yang ingin dikaji pada penelitian ini, maka dibuat 1) lembar validasi, seluruh instrumen tersebut digunakan peneliti untuk mengumpulkan data dalam penelitian. 2) Dokumentasi, teknik ini dilakukan dengan melihat dokumendokumen yang berhubungan dengan data penelitian, perekaman data, pemotretan lokasi dan infoman penelitian.

Penilaian keefektifan bahan ajar matematika berbasis ETOPAPA pada materi bangun datar di kelas IV dalam meningkatkan kualitas pembelajaran, dilakukan dengan menghitung nilai kerja kelompok, nilai belajar, analisis respons item untuk menentukan komunikasi matematis siswa, gain ternormalitas, dan hasil pengamatan proses pembelajaran. Kriteria perangkat pembelajaran dikatakan praktis jika setelah diujicobakan pada kelas eksperimen memperoleh hasil.

Berdasarkan hasil observasi di Sekolah Dasar Negeri 128 Pelembang di 
kelas IV.B, ditemukan bahwa pembelajaran tidak lagi dilakukan secara konvensional. Guru telah mengemas proses pembelajaran dengan baik, terlihat pada saat pembelajaran berlangsung. Sebelum belajar, siswa dikelompokkan kedalam beberapa kelompok yang terdiri dari 8 kelompok masing masing 5 orang. Pada saat itu, materi yang diajarkan adalah tentang bangun datar dengan menggunakan bahan ajar berbasis ETOPAPA dan contoh dari bahan ajar berbasis ETOPAPA yang biasa dijumpai dalam kehidupan sehari-hari khususnya kebudayaan lokal pariwista kota palembang yaitu jembatan ampera, benteng kuto besak, Monpera (monumen penderitaan rakyat), masjid cheng hoo, bukit siguntang, museum sultan mahmud badaruddin II, masjid agung sultan mahmud badaruddin I, gedung kantor walikota palembang, wisata alam hutan punti kayu, taman purbakala kerajaan sriwijaya, wisata kuliner martabak har, wisata kuliner pempek, Museum Sultan Badaruddin, pusat kerajinan songket, pabrik pusri, jakabaring sport city

Khusus untuk materi bangun datar siswa dibantu guru menggunakan bahan ajar berbasis ETOPAPA sebagai pembuktian. Pengguanaan bahan ajar berbasis ETOPAPA sebagai media penanaman konsep (membangun pengetahuan) dinilai sudah baik, efektif dan praktis untuk belajar. Kepraktisan bahan ajar berbasis ETOPAPA yang termaksud dalam kebudayaan daerah Palembang adalah cara peneliti dalam mempersiapkan bahan ajar tersebut (mudah didapatkan). Melihat hal itu, peneliti menemukan bahwa kebudayaan daerah kota palembang khusus untuk materi bangun datar.

\section{PEMBAHASAN}

Penelitian dan pengembangan bahan ajar matematika berbasis ETOPAPA untuk meningkatkan kualitas pembelajaran matematika di Sekolah dasar dan telah dilakukan melalui tahapan-tahapan yang telah ditentukan sebelumnya.

\section{Kevalidan Bahan Ajar Berbasis ETOPAPA}

Uji validasi dalam penelitian dan pengembangan ini dilakukan pada bahan ajar berbasis ETOPAPA yang menjadi produk hasil pengembangan. Proses validasi bahan ajar dilakukan berdasarkan saran dan masukan dari 3 validator yang terdiri dari 1 orang ahli materi, 1 orang ahli budaya daerah dan 1 orang praktisi. Validasi menggunakan lembar validasi dalam melakukan validasi produk. Hasil validasi produk bahan ajar berbasis ETOPAPA dapat dilihat pada Tabel.1.

Tabel 1: Rekapitulasi Hasil Validasi Bahan Ajar Berbasis ETOPAPA

\begin{tabular}{|c|c|c|c|c|c|c|c|c|c|c|}
\hline \multirow{3}{*}{ No } & \multirow{3}{*}{ Kode } & \multicolumn{4}{|c|}{ Skor } & & \multirow[b]{3}{*}{ TKKM } & \multirow{3}{*}{$\begin{array}{l}\text { Skor } \\
\text { Total }\end{array}$} & \multirow{3}{*}{$\begin{array}{l}\text { Rata- } \\
\text { rata } \\
\text { Skor }\end{array}$} & \multirow{3}{*}{ Kategori } \\
\hline & & \multicolumn{4}{|c|}{ Aspek Komponen } & \multirow[b]{2}{*}{$\begin{array}{l}\text { Kebuda } \\
\text { yaan }\end{array}$} & & & & \\
\hline & & Isi & Bahasa & Sajian & Penyajian & & & & & \\
\hline 1 & V-1 & 26 & 15 & 22 & 23 & 17 & 26 & 131 & 4,37 & Sangat Baik \\
\hline 4 & V-2 & 26 & 15 & 21 & 23 & 19 & 29 & 135 & 4,50 & Sangat Baik \\
\hline 3 & V-3 & 27 & 17 & 21 & 23 & 19 & 28 & 135 & 4,50 & Sangat Baik \\
\hline & & & & Rate & -rata Kese & Iruhan & & & 4,45 & Sangat Baik \\
\hline
\end{tabular}

\section{1) Keefektifan Bahan Ajar Berbasis ETOPAPA}

2) Penerapan bahan ajar bangun datar berbasis ETOPAPA dilakukan pada siswa kelas IV.B SD Negeri 
128 Palembang, yang terdiri dari 37 siswa. Peningkatan nilai belajar pada siswa diperoleh dari tes yang dilakukan siswa sebelum dan setelah proses pembelajaran atau disebut pretest dan postest. Bahan ajar bangun datar berbasis ETOPAPA dinyatakan efektif dalam meningkatkan nilai belajar jika sebanyak $\geq 75 \%$ dari siswa mendapatkan nilai belajar $\geq 65$. Nilai rata-rata klasikal pretest siswa pada uji skala luas yaitu 56,67 dan hanya 13 siswa yang memperoleh nilai > 65 dari 37 siswa, dengan demikian maka dinyatakan $35,13 \%$ siswa memperoleh nilai $\geq 65$, sedangkan nilai rata-rata klasikal postest siswa pada uji skala luas yaitu 86,37 dan persentasi jumlah siswa memperoleh nilai $\geq 65$ adalah $91,89 \%$ siswa siswa memperoleh nilai $\geq 65$. Selanjutnya, nilai ratarata pretest dan postest dapat disajikan dalam Gambar 1.

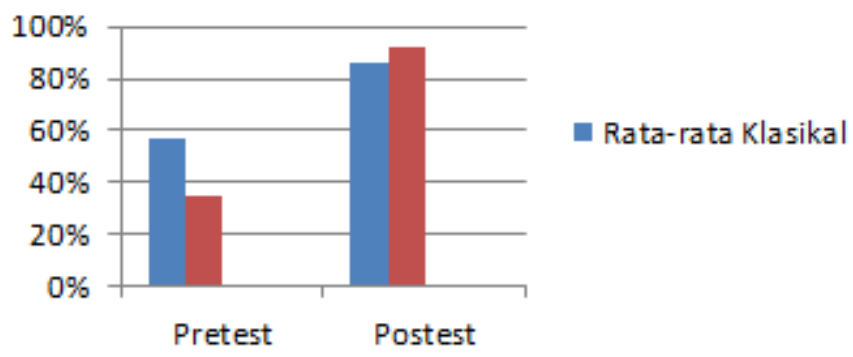

Gambar 1. Hasil Belajar Pretest dan Postest Siswa

Berdasarkan hasil perhitungan $\mathrm{N}$-gain pretest dan postest, bahan ajar bangun datar berbasis ETOPAPA dinyatakan efektif dalam peningkatan hasil belajar pada uji skala luas dikarenakan dari $35,13 \%$ siswa yang memperoleh nilai $\geq 65$, menjadi $91,89 \%$ siswa mendapat hasil belajar $\geq 65$, dangan rata-rata nilai 56,67 pada pretest dan 86,37 pada postest. Berdasarkan perhitungan, diperoleh rata-rata $\mathrm{N}$-gain skor sebesar 0,64. Skor tersebut termasuk kedalam tafsiran kategori sedang $(0,3 \leq \mathrm{g}<0,7)$.
Hal ini telah memenuhi ketentuan sebelumnya, bahwa pembelajaran menggunakan bahan ajar bangun datar berbasis ETOPAPA dikatakan efektif jika $N$-gain minimal sebesar 0,3 .

Proses pembelajaran siswa diamati menggunakan lembar pengamatan. Pengamatan dilaksanakan oleh empat orang pengamat (obsever) dengan menggunakan lembar pengamatan kegiatan siswa pada saat proses belajar mengajar.

Tabel 2 Hasil Pengamatan Proses Pembelajaran Siswa

\begin{tabular}{ccccl}
\hline No & Kode & Jumlah & Persentase & Keterangan \\
\hline 1 & V-1 & 53 & 3,53 & Sangat Aktif \\
2 & V-2 & 51 & 3,40 & Sangat Aktif \\
3 & V-3 & 53 & 3,53 & Sangat Aktif \\
4 & V-4 & 52 & 3,46 & Sangat Aktif \\
\hline & & Rata-rata & 3,48 & Sangat Aktif \\
\hline
\end{tabular}

Penggunaan bahan ajar matematika berbasis ETOPAPA materi bangun datar dinyatakan efektif pada proses pembelajaran karena memperoleh $\geq$ 
2,51, berdasarkan hasil perhitungan

\section{Kepraktisan Bahan Ajar Berbasis ETOPAPA}

Produk bahan ajar bangun datar berbasis ETOPAPA di SD perlu di uji kepraktisannya terlebih dahulu, sehingga dinyatakan layak digunakan dalam proses pembelajaran. Kepraktisan diukur dari hasil angket respons dan hasil wawancara. Angket respons hanya diberikan kepada siswa saja, sedangkan wawancara dilakukan pada guru dan siswa yang telah rata-rata $(\bar{x})$ para observer.

menggunakan bahan ajar bangun datar berbasis ETOPAPA. Pelaksanaan uji kepraktisan dilakukan setelah proses pembelajaran selesai.

\section{1) Hasil Analisis Angket Respons Siswa}

Angket respons siswa terhadap bahan ajar bangun datar berbasis ETOPAPA untuk meningkatkan kualitas pembelajaran diberikan kepada 37 responden.

Tabel 3. Hasil Analisis Angket Respons Siswa

\begin{tabular}{|c|c|c|c|c|}
\hline No & Aspek & $\begin{array}{l}\text { Pernyataan } \\
\text { Nomor }\end{array}$ & $\%$ & Kriteria \\
\hline \multirow[t]{4}{*}{1} & \multirow{4}{*}{$\begin{array}{l}\text { Proses dalam pembelajaran dengan } \\
\text { menggunakan bahan ajar matematika } \\
\text { berbasis ETOPAPA }\end{array}$} & 2 & $79 \%$ & Setuju \\
\hline & & 3 & $78 \%$ & Setuju \\
\hline & & 5 & $78 \%$ & Setuju \\
\hline & & 6 & $78 \%$ & Setuju \\
\hline \multirow[t]{3}{*}{2} & \multirow{3}{*}{$\begin{array}{l}\text { Minat siswa dalam pembelajaran } \\
\text { menggunakan bahan ajar matematika } \\
\text { berbasis ETOPAPA }\end{array}$} & 1 & $83 \%$ & Sangat Setuju \\
\hline & & 4 & $81 \%$ & Sangat Setuju \\
\hline & & 16 & $81 \%$ & Sangat Setuju \\
\hline \multirow[t]{3}{*}{3} & \multirow{3}{*}{$\begin{array}{l}\text { Penggunaan bahasa dalam bahan ajar } \\
\text { matematika berbasis ETOPAPA }\end{array}$} & 8 & $75 \%$ & Setuju \\
\hline & & 14 & $75 \%$ & Setuju \\
\hline & & 19 & $73 \%$ & Setuju \\
\hline \multirow[t]{4}{*}{4} & \multirow{4}{*}{$\begin{array}{l}\text { Pengaruh dan penerapan proses } \\
\text { pembelajaran }\end{array}$} & 9 & $72 \%$ & Setuju \\
\hline & & 10 & $79 \%$ & Setuju \\
\hline & & 11 & $81 \%$ & Sangat Setuju \\
\hline & & 15 & $71 \%$ & Setuju \\
\hline \multirow[t]{4}{*}{5} & \multirow{4}{*}{$\begin{array}{l}\text { Soal dan penilaian dalam bahan ajar } \\
\text { matematika berbasis ETOPAPA }\end{array}$} & 12 & $75 \%$ & Setuju \\
\hline & & 17 & $84 \%$ & Sangat Setuju \\
\hline & & 18 & $76 \%$ & Setuju \\
\hline & & 20 & $76 \%$ & Setuju \\
\hline 6 & $\begin{array}{l}\text { Penggunaan layout pada bahan ajar } \\
\text { matematika berbasis ETOPAPA }\end{array}$ & 13 & $80 \%$ & Sangat Setuju \\
\hline
\end{tabular}

Berdasarkan perhitungan, diperoleh rata-rata nilai persentase sebesar $85,02 \%$. Perhitungan secara rinci dapat dilihat pada lampiran analisis hasil respon siswa, hasil tersebut telah memenuhi ketentuan sebelumnya. Ketentuan yang dimaksud peneliti adalah jika rata-rata nilai persentase $\geq 75 \%$ maka dapat dinyatakan bahwa siswa memiliki respons positif terhadap bahan ajar matematika berbasis ETOPAPA. Oleh karena itu, dapat dinyatakan bahwa bahan ajar yang dikembangkan menunjukkan kepraktisan, sehingga layak digunakan dan diterapkan bagi siswa dalam pembelajaran.

\section{2) Wawancara Respons Siswa}

Wawancara respons siswa dilakukan pada 4 orang siswa yang mewakili 37 dengan hasil wawancara dapat diuraikan sebagai berikut.

> Siswa menyatakan bahwa materi pelajaran dapat mudah dipahami dengan baik setelah menggunakan bahan ajar bangun datar berbasis ETOPAPA. 
Siswa juga menyatakan bahwa pembelajaran yang menggunakan kebudayaan daerah pariwisata kota palembang merupakan bagian yang mereka sukai sehingga bisa mengenal tempat-tempat pariwisata yang ada di kota palembang.

$>$ Siswa merasa senang belajar menggunakan bahan ajar bangun datar berbasis ETOPAPA.

Setelah proses wawancara, siswa diminta tanggapannya terhadap bahan ajar bangun datar berbasis ETOPAPA secara tertulis. Beragam respons positif diberikan oleh siswa dan dapat dilihat pada lampiran.

\section{3) Wawancara Respons Guru}

Wawancara respons guru dilakukan setelah melakukan proses belajar mengajar. Berdasarkan hasil wawancara dinyatakan bahwa guru memiliki respons positif terhadap bahan ajar bangun datar berbasis ETOPAPA.
Hasil wawancara dapat diambil beberapa contohnya sebagai berikut.

$>$ Guru menyatakan bahwa bahan ajar bangun datar berbasis ETOPAPA sudah sesuai dengan Kompetensi inti (SK), Kompetensi Dasar (KD) dan Indikator dalam proses pembelajaran.

> Guru menyatakan bahwa para peserta didik sangat antusias dalam belajar menggunakan bahan ajar bangun datar berbasis ETOPAPA untuk mengetahui kebudayaan lokal khususnya pariwisata di kota Palembang.

Guru menyatakan bahwa kesan terhadap pembelajaran yang telah dilaksanakan yaitu menyenangkan, menggembirakan, ramai-ramai belajar bersama peserta didik, dan yang lebih penting lagi kita dapat mendapatkan ilmu yang bermanfaat bagi siswa dan itu sangat membahagiakan bagi saya seorang guru.

\section{SIMPULAN}

Hasil dari penelitian dan dalam melaksanakan dan pengembangan bahan ajar matematika berbasis ETOPAPA untuk meningkatkan pembelajaran matematika di sekolah dasar. Proses pembelajaran matematika dengan menggunakan bahan ajar matematika berbasis ETOPAPA yang dilakukan di SD Negeri 128 Palembang telah dilakukan dengan baik dan juga dapat meningkatkan hasil belajar siswa pada pembelajaran matematika.

Bahan ajar bangun datar berbasis ETOPAPA disesuaikan dengan kompetensi inti maupun kompetensi dasar yang terdapat pada jenjang SD kelas IV pada kurikulum 2013. Bahan ajar matematika berbasis ETOPAPA dilengkapi dengan contoh materi dan LKS bangun datar pariwisata kebudayaan lokal khususnya kota palembang.

Berdasarkan kesimpulan, bahan ajar matematika berbasis ETOPAPA telah dinyatakan valid, efektif, dan praktis. Selain itu, bahan ajar matematika berbasis ETOPAPA juga membantu guru

membudidayakan kebudayaan lokal khususnya kota palembang, sehingga siswa dapat mengoptimalkan kemampuan dan mengembangkan etomatematika.

Saran

1. Bahan ajar berbasis ETOPAPA untuk meningkatkan pembelajaran matematika disarankan agar dapat dimanfaatkan secara maksimal oleh guru.

2. Sebagai salah satu jenis penelitian yang memberikan inovasi dalam proses pembelajaran, hendaknya guru juga dapat melakukan inovasiinovasi lain yang berkaitan dengan proses pembelajaran matematika demi terciptanya pembelajaran yang baik.

3. Bahan ajar berbasis ETOPAPA dapat disosialisasikan kepada guru yang belum mengetahui eksistensi dari bahan ajar ini di sekolah-sekolah. 


\section{DAFTAR PUSTAKA}

Agustyaningrum, $\quad$ N. 2011. Implementasi Model Pembelajaran Learning Cycle 5E Untuk Meningkatkan Kemampuan Komunikasi matematika Siswa Kelas IX B SMP Negeri 2 Sleman. Makalah.Seminar Nasional Matematika dan Pendidikan Matematika di Universitas Negeri Yogyakarta. Yogyakarta, 3 Desember 2011.

Hartoyo, A. 2012. Eksplorasi Etnomatematika pada Budaya Masyarakat Dayak Perbatasan Indonesia-Malaysia Kabupaten Sanggau Kalbar. Jurnal Penelitian Pendidikan, 13(1): 1423.

Nanda. 2017. 35 tempat wisata di Palembang Sumatera Selatan dan sekitarnya. Website. Tempatwisataseru.com. https://tempatwisataseru.com/tem pat-wisata-di-palembang/ [diakses tanggal 10 Mei 2017]

Ontario. 2012. Communication in the Mathematics

Classroom.
Capacity Building Series. ISSN: 19138482

Rahayu, L.P. 2015. Pengembangan perangkat pembelajaran matematika melalui pembelajaran CTL bernuansa etnomatematika berbantuan "wayang suket". Tesis. PPSUNNES: Semarang

Rochmad. 2013. Pembelajaran Matematika Konstruktivisme Pola Pikir Induktif-Deduktif. Semarang: Universitas Negeri Semarang.

Wahyuni. A. Dkk, 2013. Peran Etnomatematika dalam membangun karakter bangsa. Prosiding. ISBN: 978-979-163539-4. Makalah dipresentasikan dalam seminar nasional Matematika dan Pendidikan Matematika dengan tema "Penguatan Peran Matematika dan Pendidikan Matematika untuk Indonesia yang Lebih Baik" pada tanggal 09 November 2013 di jurusan Pendidikan Matematika FMIPA. 